\title{
Evaluation of High-Dose Estrogen and High-Dose Estrogen plus Methyltestosterone Treatment on Cognitive Task Performance in Postmenopausal Women
}

\author{
Amy B. Wisniewskia Tam T. Nguyen ${ }^{b}$ Adrian S. Dobs ${ }^{b}$ \\ a Department of Pediatrics, Division of Pediatric Endocrinology, and bepartment of Medicine, Division of \\ Endocrinology and Metabolism, J ohns Hopkins School of Medicine, Baltimore, Md., USA
}

\section{Key Words}

Sex steroid hormones - Cognition - Perception . Memory $\cdot$ Menopause

\begin{abstract}
Objectives: To investigate the cognitive effects of highdose oral estrogen alone or in combination with oral methyltestosterone in postmenopausal women. Methods: Participants were tested with a randomized, doubleblind design on the Identical Pictures, Cube Comparisons, Building Memory and Shape Memory tasks before and after 4 months of hormone treatment. Results: Women receiving estrogen and methyltestosterone maintained a steady level of performance on the Building Memory task, whereas those receiving estrogen alone showed a decrease in performance. Conclusions: These results indicate that the addition of testosterone to high-dose estrogen replacement exerts a protective effect on memory performance in postmenopausal women.
\end{abstract}

Copyright $\odot 2002$ S. Karger AG, Base

Some evidence suggests that cognition can be influenced by androgen actions in women. A placebo-controlled investigation of the effects of a single oral dose $(0.5 \mathrm{mg})$ of testosterone on cognition in young women resulted in improved delayed-recall performance on an object-location memory test. Among female-to-male transsexuals, performance on spatial ability tasks improved following high-dose testosterone treatment to initiate phenotypic masculinization [2-4].

Several correlation studies have identified relationships between endogenous androgen levels and cognition in women. Premenopausal women with high testosterone levels outperformed those with low levels on spatial tasks [5]. Spatial performance was superior among women tested in the morning when testosterone concentration peaks compared to later in the day when testosterone production decreases [6]. Women with congenital adrenal hyperplasia, who are exposed to abnormally high concentrations of adrenal androgens prenatally (and postnatally if not compliant with treatment) exhibit enhanced performance on a variety of spatial tasks [7]. A large study of neuropsychological performance and hormonal milieu in older women revealed that participants with higher testosterone levels outperformed those with lower levels on mental status scores [8].

Some studies of androgen treatment, however, have failed to identify a clear relationship between these steroid hormones and cognitive performance in women. Surgically menopausal women improved in performance on tests of memory and logical reasoning following sex steroid replacement, regardless of estrogen and/or androgen replacement [9]. Furthermore, a double-blind, placebo-

\begin{tabular}{ll}
\hline KARGER & ( ) 2002 S. Karger AG, Basel \\
0301-0163/02/0583-0150\$18.50/0 \\
$\begin{array}{l}\text { Fax +41613061234 } \\
\text { E-Mail karger@karger.ch } \\
\text { www.karger.com }\end{array}$ & $\begin{array}{l}\text { Accessible online at: } \\
\text { www.karger.com/journals/hre }\end{array}$
\end{tabular}

Amy B. Wisniewski, PhD

600 N. Wolfe Street/Park 211

Baltimore, MD 21287 (USA)

Tel. +1 410614 5576, Fax +1 4109559773

E-Mail amy@jhu.edu 
controlled study involving DHEA treatment $(50 \mathrm{mg}$ daily for 2 weeks) in postmenopausal women revealed that cognitive performance was not affected by androgen treatment despite significant increases in DHEA, androstenedione and testosterone levels [10]. Finally, in a correlation study, investigators failed to observe any association between endogenous levels of the weak adrenal androgen DHEA and neuropsychological test performance in women [11].

The purpose of the present study was to examine the impact of 4 months of testosterone or placebo treatment in conjunction with high-dose estrogen replacement on cognitive performance in postmenopausal women. Our hypotheses were that postmenopausal women receiving methyltestosterone treatment in conjunction with highdose estrogen treatment for a period of 4 months would perform better on cognitive tasks containing a visuospatial component compared to women receiving high-dose estrogen only. We also predicted that the addition of methyltestosterone to high-dose estrogen treatment would fail to bestow a benefit in performing female-biased tasks (Identical Pictures).

\section{Methods}

\section{Participants}

Participants included 26 women (mean age 58, range 46-77 years) recruited from paid advertisements to take part in a larger study concerning the potential role of testosterone on muscle mass, bone density and cardiovascular risk factors in postmenopausal women. Inclusion criteria consisted of a bilateral oopherectomy, or a cessation of menstrual periods for at least 6 months with a consequent increase in FSH concentration $(>30 \mathrm{mIU} / \mathrm{ml})$. All participants received $0.625 \mathrm{mg}$ conjugated estrogen-replacement therapy daily, with adjuvant progestin if a uterus was present, for at least 3 months to be considered for inclusion prior to recruitment (run-in). Three women were excluded for having unusually high estradiol concentrations at baseline (mean $244 \mathrm{pg} / \mathrm{ml}$ ) which exceeded that of participants (mean $85.5 \mathrm{pg} / \mathrm{ml}$ ) by 3 standard deviations. These women were excluded because of the possibility that they did not correctly adhere to the 3-month run-in estrogen-replacement therapy requirement.

Prior to study enrollment, women were screened for general health status including blood screening (CBC, blood chemistry) and breast exams. Women were excluded from enrollment if they met any of the following: were obese (BMI $>30$ ); had uncontrolled diabetes (HgbA1c >9\%); hypertension (BP >140/90 mm Hg); had breast or uterine cancer; had hepatic, renal or cardiac disease; had a history of hypercholesterolemia, or had received any form of androgen or antidepressant during the 6 months prior to study enrollment. Further screening of neurologic disorders, mood, SES and level of education was not conducted.

Approximately half of participants experienced natural menopause and half surgical menopause. All participants received stan-
Table 1. Summary of demographic characteristics at baseline

\begin{tabular}{llll}
\hline Characteristic & $\begin{array}{l}\text { Estratab } \\
(\mathrm{n}=13)\end{array}$ & $\begin{array}{l}\text { Estratest } \\
(\mathrm{n}=13)\end{array}$ & $\mathrm{p}$ value \\
\hline Age, years & & & $\mathrm{p}>0.1$ \\
$\quad$ Mean \pm SD & $56.4 \pm 5.9$ & $59.8 \pm 8.2$ & \\
$\quad$ Range & $46-67$ & $50-77$ & $\mathrm{p}>0.1$ \\
Race & $11(84.6 \%)$ & $11(84.6 \%)$ & \\
$\quad$ White & $1(7.7 \%)$ & $0(0.0 \%)$ & \\
$\quad$ Hispanic & $1(7.7 \%)$ & $2(15.4 \%)$ & $\mathrm{p}>0.1$ \\
$\quad$ Black & $6(46.2 \%)$ & $5(38.5 \%)$ & \\
Menopause & $7(53.8 \%)$ & $8(61.5 \%)$ & \\
$\quad$ Surgical & & \\
$\quad$ Natural & &
\end{tabular}

$\mathrm{p}$ values for comparisons of the distributions of race and menopause between treatments are based on a $\chi^{2}$ test. $p$-values for comparison of the distributions of age between treatments are based on a t test.

dard estrogen-replacement therapy ( $0.625 \mathrm{mg}$ conjugated estrogens) for at least 3 months prior to enrollment. The race of participants is shown in table 1 . No differences were observed between groups for these variables.

\section{Procedure}

The design was a randomized, double-blind study. Based on a predetermined randomization code unknown to the experimenters or participants prior to study completion, women were assigned to receive one of two treatments. One treatment, Estratab ${ }^{\circledR}$, consisted of a daily oral preparation of estrogen in the form of $1.25 \mathrm{mg}$ esterified estrogen (E group) for 4 months. The second treatment, Estratest ${ }^{\circledR}$, consisted of a daily oral preparation of estrogen plus methyltestosterone in the form of $1.25 \mathrm{mg}$ esterified estrogen $+2.50 \mathrm{mg}$ methyltestosterone (E+T group) for 4 months. The oral estrogen dose was doubled upon entry into the study to minimize unwanted virilization such as hirsutism or clitoral enlargement in the $\mathrm{E}+\mathrm{T}$ group. Medication was taken for both treatment groups between 08.00 and $10.00 \mathrm{~h}$. Participants were tested twice, once before treatment (session 1) and again following 4 months of $\mathrm{E}$ or $\mathrm{E}+\mathrm{T}$ treatment (session 2). Testing occurred between 08.00 and $10.00 \mathrm{~h}$ at an outpatient clinic at the Johns Hopkins Hospital.

Medication was provided by Solvay Pharmaceuticals, Inc. (Marrietta, GA). No progestin was administered during the study period, however women with a uterus were administered progestin $(10 \mathrm{mg}$ daily) for 14 days per month following study completion. The research reported here was approved by the Joint Committee of Clinical Investigations of the Johns Hopkins University, School of Medicine (Baltimore, MD). Written, informed consent was obtained from all subjects prior to participation.

\section{Endocrine Assays}

All participants fasted for a minimum of $12 \mathrm{~h}$ before morning blood draw. Blood was drawn with serum separator tubes for hormone assays and blood chemistry. Sera and plasma were separated at 
$4^{\circ} \mathrm{C}$ for $15 \mathrm{~min} 2,000 \mathrm{rpm}$. Sera were stored at $-70^{\circ} \mathrm{C}$ until analyzed, for a period of up to 7 months. Samples were analyzed by Quest Diagnostics Laboratory (Owings Mills, MD). For each test, all samples were analyzed in a single assay. The radioimmunoassay procedure for LH consisted of a two-site chemiluminometric immunoassay for intact $\mathrm{LH}$ with a $3.1 \%$ intra-assay coefficient of variation and sensitivity of $4.2 \mathrm{mIU} / \mathrm{ml}$. Radioimmunoassay for FSH consisted of a two-site chemiluminometric immunoassay for intact FSH with a $2.6 \%$ intra-assay coefficient of variation and a sensitivity of $4.0 \mathrm{mIU} /$ $\mathrm{ml}$. Sequential radioimmunoassay with bound/free separation by PEG-accelerated second antibody without extraction, and 5.5\% intra-assay coefficient of variation and a sensitivity of $16.9 \mathrm{pg} / \mathrm{ml}$ was performed for estradiol. A competitive radioimmunoassay for total testosterone (TT) consisted of double antibody/PEG-precipitated separation with organic extract and celite chromatography pretreatment and tritiated testosterone added to correct for extraction recovery, with a $9.2 \%$ intra-assay coefficient of variation and a sensitivity of $13.8 \mathrm{ng} / \mathrm{dl}$. Radioimmunoassay for free testosterone (FT) incubated the sample with ${ }^{3} \mathrm{H}$-testosterone, and testosterone bound to sex hormone-binding globulin (SHBG) was precipitated with ammonium sulfate. The aliquot was counted and percent FF estimated with the equation free $=\%$ free $\times$ TT, with a $10 \%$ intra-assay coefficient of variation and a sensitivity of $5.0 \mathrm{ng} / \mathrm{dl}$. A competitive radioimmunoassay for SHBG used double-antibody/PEG-precipitation separation with a $4.8 \%$ intra-assay coefficient of variation and a sensitivity of $16 \mathrm{nmol} / 1$.

\section{Cognitive Measures}

All cognitive tasks were taken with permission from the kit of Factor-Referenced Cognitive Tests (Educational Testing Services, Princeton NJ). Tasks were administered in a fixed order (Identical Pictures, Cube Comparisons, Building Memory, Shape Memory) for each participant at each test session by an experienced technician. A task that favors females such as Identical Pictures (with a lowmedium effect size of approximately 0.2 ) and a task that favors males such as Cube Comparisons (with a stronger effect size of approximately 1.0 or greater) were used as it seemed reasonable that these might be sensitive to sex hormone treatment in postmenopausal women [12]. Memory tests were employed in light of reports that sex hormone replacement improves verbal and figural memory in postmenopausal women $[13,14]$. The Building Memory test was chosen because males typically outperform females on measures of route learning as well as knowledge of Euclidean properties [15]. The Shape Memory test was administered to assess learning and memory for abstract visuospatial stimuli, as women have been shown to outperform men on remembering positions and matching objects as well as nonsense shapes [16, 17].

Identical Pictures Test [18] (Copyright 1962, 1975 ETS). This test measures the ability to match identical items (e.g., faces, animals, houses) from a series of similar-appearing line drawings, and is documented to elicit a sex difference in performance that favors females [19]. Participants were allotted $1.5 \mathrm{~min}$ to complete 48 test items. The dependent measure is the number of correct matches.

Cube Comparisons Test [18] (Copyright 1962, 1976 ETS). This test measures the ability to mentally rotate a line drawing of a 3dimensional cube, and is documented to elicit a sex difference in favor of males. Participants were allotted $3 \mathrm{~min}$ to mentally rotate 21 test items. The dependent measure is the correct identification of the mental rotation of each test item from series of forced-choice line drawings.
Building Memory Test [18] (Copyright 1975, ETS). This test measures the visual memory of building locations on a street map. Participants were allotted 4 min to study and memorize a map, followed by an additional $4 \mathrm{~min}$ in which to indicate the correct location of 12 buildings on a test map. The dependent measure is the accurate placement of the buildings on a test map.

Shape Memory Test [18] (Copyright 1975, 1976 ETS). This test measures the visual memory of a group of shapes and their position in relation to each other. Participants were allotted 4 min to study and memorize a visual scene, followed by another $4 \mathrm{~min}$ in which to respond to 16 test items. The dependent measure is the number of correct shapes, properly arranged in relation to one another, recognized from a group of forced-choice distracter shapes and arrangements.

Different but comparable test items were used in sessions 1 and 2 for all tasks.

\section{Data Analysis}

Differences in task performance and hormone levels between women receiving $\mathrm{E}$ or $\mathrm{E}+\mathrm{T}$ treatment were assessed with a 2-factor (treatment group $\times$ test session), mixed analysis of variance for each cognitive task and hormone measured. Post hoc comparisons were conducted using Tukey's method of multiple comparisons. Mean differences were considered statistically significant for $\mathrm{p}<0.05$.

\section{Results}

\section{Endocrine Assays}

Hormone levels for each group at each test session are presented in table 2. As expected, a main effect of test session was observed for estradiol concentrations $(\mathrm{F}(1,24)=$ $29.7, p<0.001)$, where the mean concentration increased following treatment for both groups. A main effect of test session was observed for TT concentrations $(F(1,22)=$ 12.2, $\mathrm{p}<0.005)$, LH concentrations $(\mathrm{F}(1,23)=6.58, \mathrm{p}<$ $0.05)$, and FSH concentrations $(F(1,23)=6.7, p<0.05)$. A test session $\times$ treatment group interaction approached significance for $\mathrm{LH}$ concentrations $(\mathrm{F}(1,23)=3.0, \mathrm{p}=$ $0.09)$. Post hoc analysis revealed a decrease in LH concentrations for the E+T, but not the E group, across test sessions $(p<0.05)$. Finally, a test session $\times$ treatment group interaction was observed for SHBG concentrations $(\mathrm{F}(1,24)=4.8, \mathrm{p}<0.05)$ with mean concentrations decreasing from session 1 to session 2 for the $\mathrm{E}+\mathrm{T}$ group.

\section{Cognitive Performance}

Identical Pictures. Numerical performance increased for the E group, and decreased for the E+T group, following 4 months of treatment as shown in figure 1 and table 3. No main effects of test session or treatment were observed, however a significant treatment by test session interaction was noted $(\mathrm{F}(1,24)=4.41, \mathrm{p}<0.05)$. 


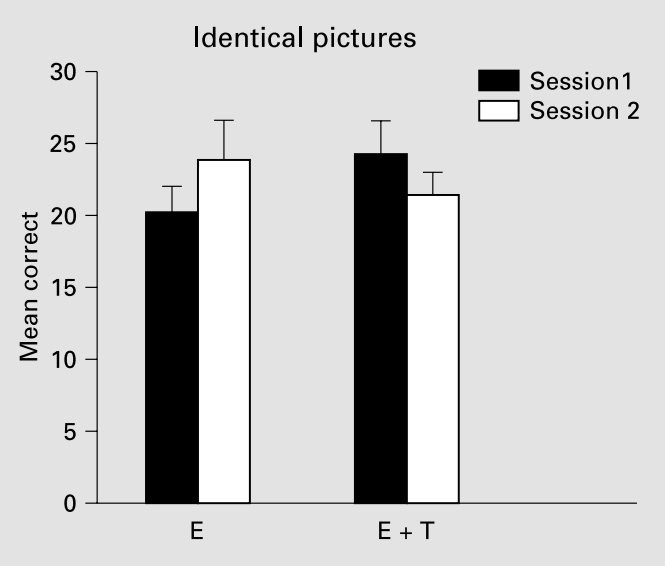

Fig. 1. Mean number of correct responses on the Identical Pictures task. Error bars represent \pm 1 SEM. No main effects of test session or treatment group were observed, however a significant session $\times$ treatment interaction was noted.

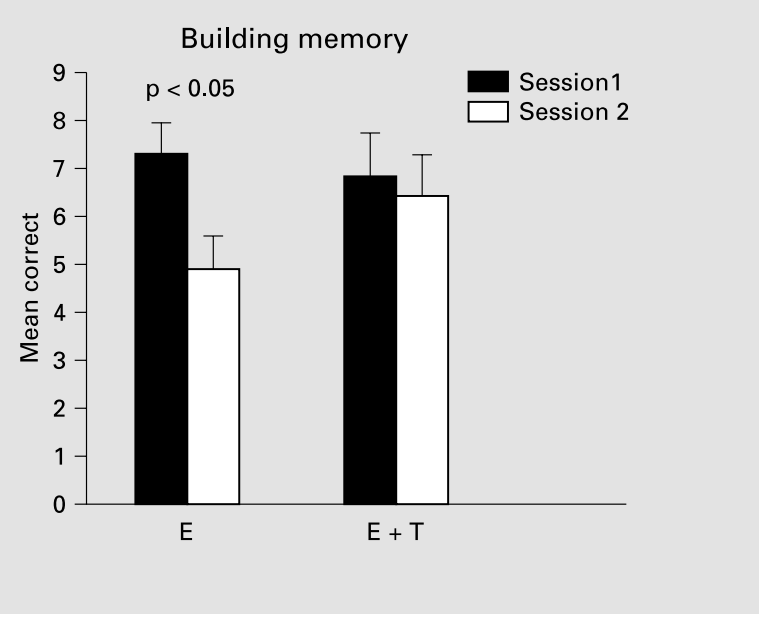

Fig. 2. Mean number of correct responses on the Building Memory task. Error bars represent \pm 1 SEM. Women in the E group showed a decrease in their performance across test sessions 1 and 2, while women in the $\mathrm{E}+\mathrm{T}$ group maintained a steady level of performance.
Table 2. Hormone concentrations for participants (mean \pm SEM)

\begin{tabular}{|c|c|c|c|c|}
\hline & \multicolumn{2}{|l|}{ E group } & \multicolumn{2}{|l|}{$\mathrm{E}+\mathrm{T}$ group } \\
\hline & session 1 & session 2 & session 1 & session 2 \\
\hline Estradiol, $\mathrm{pg} / \mathrm{ml}$ & $85.3 \pm 14.8$ & $209.8 \pm 19.6$ & $85.8 \pm 13.4$ & $283.2 \pm 40.7$ \\
\hline $\mathrm{TT}, \mathrm{ng} / \mathrm{dl}$ & $16.7 \pm 2.9$ & $6.7 \pm 2.7$ & $16.6 \pm 3.1$ & $8.5 \pm 1.7$ \\
\hline $\mathrm{FT}, \mathrm{ng} / \mathrm{dl}$ & $2.0 \pm 0.4$ & $2.7 \pm 0.9$ & $3.4 \pm 0.8$ & $3.3 \pm 0.6$ \\
\hline $\mathrm{LH}, \mathrm{mIU} / \mathrm{ml}$ & $24.6 \pm 4.2$ & $22.9 \pm 3.1$ & $28.5 \pm 4.2$ & $19.4 \pm 2.7$ \\
\hline $\mathrm{FSH}, \mathrm{mIU} / \mathrm{ml}$ & $38.4 \pm 7.7$ & $32.1 \pm 5.5$ & $40.7 \pm 5.6$ & $30.0 \pm 4.8$ \\
\hline SHBG, nmol/1 & $43.6 \pm 19.7$ & $44 \pm 4.7$ & $27.12 \pm 7.1$ & $8.51 \pm 1.2$ \\
\hline
\end{tabular}

Due to the large range in ages of the participants, a MANCOVA with age as a covariate was performed and revealed the same pattern of results with no main effects of test session or treatment $(F(1,23)=0.25, p>0.05)$. Additionally, differences in SHBG concentrations at session 1 between groups could potentially contribute to the baseline difference in performance on the Identical Pictures task. To address this possible confound, a MANCOVA was performed with SHBG concentration at session 1 as a covariate and again revealed no main effects of test session or treatment $(\mathrm{F}(1,23)=1.34, \mathrm{p}>0.05)$.

Cube Comparisons. Performance improved for both groups across test sessions, however this improvement only approached statistical significance $(\mathrm{F}(1,23)=2.949$, $p=0.09)$. No other effects were significant.
Table 3. Scores for the Identical Pictures test (mean \pm SEM)

\begin{tabular}{lll}
\hline & E group & E+T group \\
\hline Session 1 & $20.5 \pm 1.7$ & $24.7 \pm 2.3$ \\
Session 2 & $24.2 \pm 2.7$ & $21.8 \pm 1.8$
\end{tabular}

Building Memory. A main effect of test session was observed, with performance declining across sessions for both groups $(\mathrm{F}(1,23)=14.08, \mathrm{p}<0.01)$ as indicated in table 5 and figure 2 . A treatment $\times$ test session interaction was observed $(\mathrm{F}(1,23)=6.948, \mathrm{p}<0.05)$. Post hoc comparison revealed that this effect was due to a decrease 
Table 4. Scores for the Cube Comparisons test (mean \pm SEM)

\begin{tabular}{lcc}
\hline & E group & E+T group \\
\hline Session 1 & $5.9 \pm 0.6$ & $6.9 \pm 1.0$ \\
Session 2 & $7.1 \pm 0.8$ & $8.3 \pm 1.2$ \\
\hline
\end{tabular}

Table 5. Scores for the Building Memory test (mean \pm SEM)

\begin{tabular}{lcc}
\hline & E group & E+T group \\
\hline Session 1 & $7.4 \pm 0.7$ & $7.0 \pm 0.9$ \\
Session 2 & $5.0 \pm 0.7$ & $6.6 \pm 0.9$ \\
\hline
\end{tabular}

Table 6. Scores for the Shape Memory test (mean \pm SEM)

\begin{tabular}{lrr}
\hline & E Group & E+T group \\
\hline Session 1 & $9.8 \pm 0.8$ & $10.8 \pm 0.5$ \\
Session 2 & $12.1 \pm 1.0$ & $12.2 \pm 0.6$ \\
\hline
\end{tabular}

in the $\mathrm{E}$ group $(\mathrm{p}<0.05)$ but not the $\mathrm{E}+\mathrm{T}$ group $(\mathrm{p}>0.1)$ across sessions. Post hoc comparison also revealed that the $\mathrm{E}$ and $\mathrm{E}+\mathrm{T}$ groups did not differ in baseline performance on this task $(p>0.1)$. No other effects were significant.

Shape Memory. Performance improved across test sessions for both the $\mathrm{E}$ and $\mathrm{E}+\mathrm{T}$ groups, $(\mathrm{F}(1,23)=7.816, \mathrm{p}<$ 0.05 ) as shown in table 6 . No other effects were significant.

\section{Discussion}

The present investigation extends our understanding of sex hormone-replacement therapy on cognitive performance in postmenopausal women, to include testosterone in conjunction with estrogen treatment. Our original hypotheses were that postmenopausal women receiving methyltestosterone treatment in conjunction with highdose estrogen treatment would perform better on cognitive tasks containing a visual spatial component compared to women receiving high-dose estrogen alone. We also predicted that the addition of methyltestosterone to high-dose estrogen treatment would fail to improve performance on female-biased tasks that do not include a visual spatial processing component.

Data collected in this study partially support our original predictions. Women receiving E+T maintained a steady level of performance on the Building Memory task between test sessions, while women receiving $\mathrm{E}$ alone exhibited a decrease in performance. This suggests that testosterone replacement is protective for performance on this task in the context of high-dose E replacement in postmenopausal women. This result is consistent with previous reports of a male advantage for route learning. It is possible that Building Memory and route learning tasks share one or more processing components that are harmed by high-dose estrogen alone, but protected when testosterone is included at sufficient levels.
In two tasks, Cube Comparisons and Shape Memory, performance improved across test sessions for both subject groups. These results do not support our original hypothesis, that the $\mathrm{E}+\mathrm{T}$ group should outperform the $\mathrm{E}$ group on these visual tasks. Due to the necessity of a doubling estrogen dose for both groups in this study, it is impossible to know if this improved performance was a result of practice effects, increasing estrogen dose or a combination of these two factors. It may also be the case that higher doses of testosterone are required to see the predicted differences on these tasks. Future studies of this type should include placebo groups receiving no sex hormone replacement to better understand these patterns of performance.

As expected, both treatment groups showed a significant increase in estradiol concentrations after doubling their replacement dose of estrogen across test sessions. A significant decrease in TT production was also observed following 4 months of treatment for both groups. This can be explained by the suppression of gonadotropins by the increased E replacement across test sessions, thus presumably leading to decreased ovarian androgen production [20]. Although methyltestosterone cannot be measured with radioimmunoassays developed for TT and FT, it can be indirectly assessed with LH and SHBG radioimmunoassays. In general, SHBG and LH concentrations decrease with increased androgens $[21,22]$, and the E+T group experienced a decrease in both following 4 months of methyltestosterone treatment. Post hoc comparison revealed that this decrease was statistically significant for LH.

Roughly half of circulating TT is produced either directly or indirectly from the adrenal glands in women [23]. Women experience peak adrenal androgen production during their early to mid adulthood [24]. If physiological concentrations of androgens influence cognitive performance in women, then a decrease in testosterone production associated with both normal adrenal aging as well as menopause could be associated with cognitive changes in older women. The present study partially supports this 
logic in that testosterone treatment protected against the decrease in Building Memory performance associated with estrogen-replacement in postmenopausal women. It would be of interest to investigate the impact of E+T replacement on verbal and long-term rote memory performance in postmenopausal women [25].

\section{Acknowledgements}

Portions of this manuscript were presented at the 1999 Endocrine Society Meeting, San Diego, Calif., USA and the 1999 North American Menopause Society Meeting, New York, N.Y., USA This research was partially supported by the Johns Hopkins University School of Medicine General Clinical Research Center, NIH/NCRR grant M01 RR00052. This research was also funded in part by Solvay Pharmaceuticals, Inc., Marietta, Ga., USA.

\section{References}

1 Postma A, Meyer G, Tuiten A, van Honk J, Kessels RPC, Thijssen J: Effects of testosterone administration on selective aspects of objectlocation memory in healthy young women. Psychoneuroendocrinology 2000;25:563-575.

2 Slabbekoorn D, van Goozen SH, Megens J, Gooren LJ, Cohen-Kettenis PT: Activating effects of cross-sex hormones on cognitive functioning: A study of short-term and long-term hormone effects in transsexuals. Psychoneuroendocrinology 1999;24:423-447.

3 Van Goozen SH, Cohen-Kettenis PT, Gooren LJ, Frijda NH, Van de Poll NE: Activating effects of androgens on cognitive performance: Causal evidence in a group of female-to-male transsexuals. Neuropsychology $1994 ; 32: 1153$ 1157.

4 Van Goozen SH, Cohen-Kettenis PT, Gooren LJ, Frijda NH, Van de Poll NE: Gender differences in behaviour: Activating effects of crosssex hormones. Psychoneuroendocrinology 1995;20:343-363.

5 Gouchie C, Kimura D: The relationship between testosterone levels and cognitive ability patterns. Psychoneuroendocrinology 1991;16: 323-334.

6 Moffat SD, Hampson E: A curvilinear relationship between testosterone and spatial cognition in humans: Possible influence of hand preference. Psychoneuroendocrinology 1996;21: 323-337.

7 Resnick SM, Berenbaum SA, Gottesman II, Bouchard TJ:. Early hormonal influences on cognitive functioning in congenital adrenal hyperplasia. Dev Psychol 1986;22:191-198.
8 Barrett-Connor E, Goodman-Gruen D: Cognitive function and endogenous sex hormones in older women. J Am Geriatr Soc 1999;47:1289_ 1293.

9 Sherwin BB: Estrogen and/or androgen replacement therapy and cognitive functioning in surgically menopausal women. Psychoneuroendocrinology 1988;13:345-357.

10 Wolf OT, Neumann O, Hellhammer DH, Geiben AC, Strasburger CJ, Dressendörfer RA, Pirke KM, Kirschbaum C: Effects of a twoweek physiological dehydroepiandrosterone substitution on cognitive performance and well-being in healthy elderly women and men. J Clin Endocrinol Metab 1997;82:2363-2367.

11 Barrett-Connor E, Edelstein SL: A prospective study of dehydroepiandrosterone sulfate and cognitive function in an older population. J Am Geriatr Soc 1994;42:420-423.

12 Kimura D: Sex differences in the brain. Sci Am 1992;213:119-125.

13 Resnick SM, Maki PM, Gorski S, Kraut MA, Zonderman AB: Effects of estrogen replacement therapy on PET cerebral blood flow and neuropsychological performance. Horm Behav 1998;34:171-182.

14 Sherwin BB: Estrogen and cognitive functioning in women. Proc Soc Exp Biol Med 1998; 217:17-22.

15 Galea LAM, Kimura D: Sex differences in route-learning. Pers Indiv Diff 1993;14:53-65.

16 Eals M, Silverman I: The hunter-gatherers theory of spatial sex differences: Proximate factors mediating the female advantage in recall of object arrays. Ethol Sociobiol 1994;15:95-105.
17 McBurney DH, Gaulin SJC, Devineni T, Adams C: Superior spatial memory of women: Stronger evidence for the gathering hypothesis. Evol Hum Behav 1997;18:165-174.

18 Ekstrom RB, French JW, Harman HH, Derman D: Kit of factor-referenced cognitive tests, 1976. Educational Testing Service, Princeton, N.J.

19 Kimura D: Sex and cognition. Cambridge, Mass., The MIT Press, 1999.

20 Azziz R, Gay F: The treatment of hyperandrogenism with oral contraceptives. Semin Reprod Endocrinol 1989; 7:246-254.

21 Rosenfield RL: Plasma testosterone binding globulin and indexes of the concentration of unbound plasma androgens in normal and hirsute subjects. J Clin Endocrinol Metab 1971; 32:717-728.

22 Simon JA, Mazer NA, Wekselman K: Safety profile: Transdermal testosterone treatment of women after oopherectomy. Obstet Gynecol 2001;97:S10-S11.

23 Maroulis GB: Evaluation of hirsutism and hyperandrogenemia; in Wallach EE, Kempers RD (eds): Modern Trends in Infertility and Conception Control. Philadelphia, Harper \& Row, 1982, vol 2.

24 Parker LN: Adrenal Androgens in Clinical Medicine. San Diego, Academic Press, 1989.

25 Carlson E, Sherwin BB: Higher levels of plasma estradiol and testosterone in healthy elderly men compared with age-matched women may protect aspects of explicit memory. Menopause 2000;7:168-177.
High-Dose Estrogen plus

Methyltestosterone in Postmenopausal Women
Horm Res 2002;58:150-155 
Copyright: S. Karger AG, Basel 2002. Reproduced with the permission of S. Karger AG, Basel. Further reproduction or distribution (electronic or otherwise) is prohibited without permission from the copyright holder. 